\title{
Exploration and Practice of Introductory Curriculum on Mechanical Engineering
}

\author{
Xiao-Gui Zhang ${ }^{\mathrm{a}}$, Jun-Jie Xiao ${ }^{\mathrm{b}}$ \\ Department of Mechanical Engineering, Beijing Institute of Graphic Communication, Beijing, China

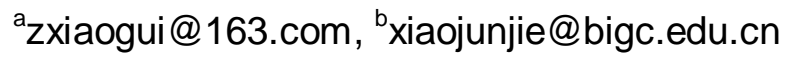

Keywords: Mechanical engineering, Curriculum construction, Teaching content, Teaching practice.

\begin{abstract}
The introductory of mechanical engineering is a new opened elective course mechanical in the engineering major. It plays a positive role in guiding students to understand the major itself, the development of it and the future employment prospects, improving the students' interest in learning, cultivating quality. The article based on the characteristics of the school and major in mechanical engineering, has carried on the preliminary discussion and practice in the teaching practice on how to strengthen the construction of an introductory course in mechanical engineering and teaching practice, and to explore the reasonable curriculum system, teaching content, teaching methods and teaching means, etc. while the teaching practice.
\end{abstract}

\section{Introduction}

The introductory of mechanical engineering is an introductory theory course for high professional engineering college and university, and also is one of the earliest of elective courses. Through learning this course, students got a complete and clear understanding, built the theoretical knowledge frame and basic skills that professional students should master. It is also an introduction of the course. According to the development history and the real situation of mechanical engineering, the course can arouse the students' interest in learning and provide the correct guidance for the future professional study and professional development. Through learning this course, it makes students get a basic understanding about the basic concept, basic knowledge of mechanical engineering and development situation of mechanical engineering, and the related engineering new technology, process and development of disciplines, preliminary have the further understanding to major in mechanical engineering and related learning ability.

At the same time, the introductory of mechanical engineering is an important course in quality education and plays a very important role in improving the students' interest in learning, in the process of the cultivation of senior engineering and technical personnel.

This paper gets a deeper thinking and practice on strengthening of the curriculum construction and course of the introductory of mechanical engineering teaching practice, setting up reasonable curriculum system, perfecting the teaching contents, and exploring a reasonable teaching mode and teaching method.

\section{The purpose of setting the introductory of mechanical engineering and the present situation}

To the university freshman, mechanical engineering of high engineering college and university is very difficult to understand. They usually can't understand the connotation of the mechanical engineering, disciplines, curriculum system and course. It is also unclear about the future development of professional, working scope and employment prospects, development present situation and development trend at home and abroad, the gap with foreign aspects. A lack of understanding of the professional at the same time, leads some students after entering university, feel puzzled, lack of learning goals and motivation, blindly to change professional, study interest is not that high. Based on these considerations with careful discussion, period for the introductory of mechanical engineering is 32 hours.

In such a background and premise to set up an introductory course in mechanical engineering, without early accumulations, the course needs to build urgently. Because of the decision to open an 
introductory course in mechanical engineering, we mainly discussed about the teaching of the course system, outline, content, mode and method and strengthen the corresponding construction.

\section{The system construction of the introductory of mechanical engineering}

According to the opinion of the backbone teachers, we make the course syllabus. The course content is divided into five main topics, namely the cultivation of the mechanical engineering solutions, mechanical engineering education, the history of the development of mechanical engineering at home and abroad; basic knowledge of mechanical engineering; mechanical manufacturing technology; robot technology and printing machine technology and so on.

Each project will get some research specialty and senior teachers to teach. According to the basis of the mechanical engineering technology, the requirement of the comprehensive, forward-looking, we introduce to students major in mechanical engineering development and progress of human society, the relationship between the development of mechanical engineering in the new century talent education and training.

In addition to the teaching of the basic content of modern mechanical engineering research and development, we also introduce the knowledge system to complete the project, namely the introduction of engineering mechanics, engineering materials, the basic knowledge, such as mechanical engineering drawing expression composed of mechanical principle, common mechanical parts and application and manufacturing technology of mechanical products, robotics, printing machinery structure and the correlative theory and practice [1] [2].

Especially the explain on the latest achievements of mechanical engineering and foresee of development in the new century. With all-round perspective to explore the academic field of vision, we can clear mechanical professional prospect of engineering application.

\section{The concept construction of the introductory of mechanical engineering}

The further development of curriculum is the foundation of improve the quality of teaching. In the process of teaching, we make the introductory of mechanical engineering as a new course in the focus of the mechanical engineering construction, constantly explore and improve on the teaching content to improve the teaching quality and effect of this course [3].

\section{The development of mechanical engineering at home and abroad and mechanical engineering professional talent training scheme}

Through the introduction of the history and status of mechanical engineering at home and abroad, we make students realize the industry to develop very quickly in our country. Our country has got to the top of the world with high-speed rail technology, military technology and other aspects, but there is a certain gap between our manufacturing level compared with the world such as America, Japan and other developed countries. These mainly displays in the weak technical innovation ability, backward manufacturing process equipment, product quality and the technology, technical development capability, low productivity. We should stimulate students' learning enthusiasm and initiative, for mechanical industry and the progress of the society to study hard, at the same time to make the students understand the characteristics of the mechanical engineering professional training objectives, professional requirements and training, knowledge structure and ability structure, the structure of the curriculum system, in order to control the market demand, and to make the students more confidence in the future job prospects. Make the students to master the relationship between the public basic course, the foundation courses and professional courses, the group's role in this technical field, for subsequent professional learning and lay a solid theoretical foundation for the future employment and discipline foundation. For example: the importance of engineering drawing course is that it is not only a basic course, at the same time it requires to express clearly design idea in the form of technical documents, so it asks the students not only can use $2 \mathrm{~d}$ or $3 \mathrm{~d}$ drawing, but also can design and mark the tolerance and so on. Students in college should attach importance to these basic courses, so in introduction to mechanical engineering class, we should tell students clear cohesive relationship between courses, make students know the importance of basic courses in 
professional study, guide the students in junior year, take the time to set up the ideal of life and goals, and strive to become a creative talents.

\section{Introduction of the basic theories of mechanical engineering}

We emphasize the importance of professional foundation courses and learning methods, such as theoretical mechanics, material mechanics, mechanical principle and design. Basic course is not only the basis of professional course, but also is the exam content for a lot of colleges and universities to recruit graduate students. The students realize the stakes of each course, then pay more attention and get fully it will be more fully preparation to avoid and reduce some problems in the future. Through the case, images, animation, and a large number of video introductions of basic institutions of engineering used in all kinds, students could understand the types of common mechanical parts, basic structure and the type of machinery involved in all kinds of metal materials, brand performance and common way to express; An understanding of the mechanical parts made of these metal materials in the process of the practical work of all kinds of basic deformation and mechanical characteristics.

\section{The introduction of mechanical manufacturing technology}

The mechanical engineering has a very wide range of knowledge and theory. We only introduce the basic method of mechanical processing and various methods applicable material performance and precision of the parts and components made of parts processing process and measuring the basic method, and introduces the numerical control processing technology, special processing, computer integrated manufacturing system, modern manufacturing technology such as intelligent manufacturing system.

\section{The introduction of robot technology}

We mainly introduce the origin and definition of robots. Robot is a kind of automatic machine. The difference is this kind of machine has some similar to people or biological intelligence ability, and is the product of mechanical and automation. We demand the students to understand robots at home and abroad, research results and applications, clearly understands of the main work and research for the mechanical engineering students in the field of robot technology.

\section{The introduction of printing and packaging machinery technology}

Mechanical engineering and adaptation of directionality is very strong. In addition to some general knowledge of mechanical engineering and technology, we also introduce the types of printing machinery, application situation and characteristics of the development trend of the future. We introduce the commonly used post-press processing machinery, packaging machinery, suitable working conditions and development direction in the future. Also introduce some current more cutting-edge technology at the same time, such as $3 \mathrm{~d}$ printing, printing of electronic technology, to make the students understand mechanical engineering academic frontiers of knowledge.

\section{The active adoption of reasonable teaching methods and teaching means}

Mechanical engineering involves a wider theory and knowledge, which is very abstract and hard to understand for a freshman. Adopting reasonable, scientific and effective teaching methods and teaching means is the important way to improve students' learning enthusiasm, strengthen students' learning effect .In the teaching process, we invite the experts and scholars combined with their own teaching and research development situation of related disciplines of knowledge and use of methods such as case teaching, social practice, to maximum the limit set by an introductory course in mechanical engineering, stimulate students' learning interest and enthusiasm, and to improve the ability of understanding of the problem.

In the mechanical engineering teaching, we should closely combine the actual conditions of mechanical engineering, pay attention to emphasize the case teaching, application, typical system, perfecting the teaching case, display a variety of mechanical engineering as examples, to guide students in understanding of mechanical engineering in the important position of daily life and production practice, and to inspire the students' interest and enthusiasm for professional learning, in 
order to achieve the teaching purpose of this course. At the same time, we advocate students to participate in social production and practice, organize students to visit the enterprise and laboratory to feel the corporate culture, and properly choose some chapters, combining with the equipment in the laboratory or manufacturing site scene teaching, make students understand the importance of the diversity of mechanical equipment and in social life, increase the perceptual knowledge.

As to the teaching method, we make full use of the blackboard writing, physical objects, images, animation, video and other modern teaching means to assist teaching and combined with engineering examples, to introduce the academic frontiers of knowledge and the future development trend, in order to improve the teaching effect. In the teaching files, we gradually improve multimedia teaching form complete, vivid teaching multimedia, make some animations and videos, present to the students with the related equipment in the form of animation or image, to deepen understanding through vivid dynamic video, then to enhance practical teaching effect [4] [5].

During the teaching, to encourage students' way of thinking to develop individuation, we guide students to observe, analyse and solve problems, encourage students to apply modern techniques to collect data both at home and abroad, and broaden the horizons, to get more knowledge information through multi-angle and multi-channel. We may leave a small paper as homework to let students discuss interesting issues in groups, to promote active learning the enthusiasm. The course assessment takes the procedural appraisal management mode. The course of the assessment is made of normal operations results, attendance records and class paper grades.

\section{Conclusions}

We optimize the teaching content and improve the teaching system according to professional training programs and basic courses teaching requirements. We also should strengthen the team construction, curriculum construction and actively teaching reform work, to improve the teaching level during the construction. We should keep continuous development and the introduction of training students' learning ability, innovation ability of teaching mode and teaching method, to improve the students' interest in learning. Through the course construction, we can form good teaching system, perfect the teaching contents and teaching methods, to achieve the basic aim of course: It can effectively stimulate students' interest in learning, guide students to consciously learning and set a goal and work on life.

\section{Acknowledgement}

This work was supported by Course Construction on Introductory to Mechanical Engineering Projects Funded by Beijing Institute of Graphic Communication and by Fine Course Construction of Modern Design Theory and Method Projects of Beijing Institute of Graphic Communication.

\section{References}

[1] Xianmin Zhang, Zhong Chen, Introductory to Mechanical Engineering. Huazhong University of Science and Technology Press, 2013.

[2] Yongxian Liu, Introductory to Mechanical Engineering. Machinery Industry Press. 2010.

[3] Hongling Hou, Exploration of Bilingual Teaching on Introductory to Mechanical Engineering, Science and Technology Innovation Herald, No.10(2010), pp.167-168.

[4] Xiaogui Zhang, Yanping Du, Exploration in the Curriculum and Teaching Based Cultivation of Innovation Capabilities for Graduate Students, Advanced Materials Research Vols. 655-657 (2013) pp2132-2135.

[5] Xiaogui Zhang, Jifei Cai, Research on Cultivating of Engineering Capability Based on Course, Advanced Materials Research Vols. 889-890 (2014) pp1672 -1675. 